\title{
Self-Extrusion of Unknowingly Ingested Sewing Needle through the Skin of Neck
}

\author{
Digvijay Singh Rawat ${ }^{1}$, Sikandar Singh ${ }^{1}$, Sudhanshu Pandey ${ }^{1}$, Tarun Ojha ${ }^{2}$, P. C. Verma ${ }^{1}$ \\ ${ }^{1}$ Department of Otorhinolaryngology, JLN Medical College, Ajmer, India \\ ${ }^{2}$ Department of Otorhinolaryngology, Mahatma Gandhi Medical College, Jaipur, India \\ Email: drdigvijaysingh231@gmail.com
}

Received May 19, 2013; revised June 12, 2013; accepted June 30, 2013

Copyright (C) 2013 Digvijay Singh Rawat et al. This is an open access article distributed under the Creative Commons Attribution License, which permits unrestricted use, distribution, and reproduction in any medium, provided the original work is properly cited.

\begin{abstract}
Foreign body ingestion is a common presentation but the extraluminal migration of a foreign body is rare. A 46-year-old man presented with protruded sharp swelling left side of neck, X-rays and CT scan of the neck showed a needle migrating from the pyriform fossa to the skin. Carotid angiography was also done to see the relations of foreign body with great vessels. Transcutaneous removal of foreign body was done under general anesthesia. The migrated foreign body was a sewing needle which patient unknowingly swallowed two days back. Migrated ingested foreign bodies from the upper digestive tract have the potential to cause life-threatening complications. Cases of spontaneous expulsion of ingested foreign bodies to the skin of the neck are quite rare.
\end{abstract}

Keywords: Foreign Body; Migratory Foreign Body; Ingested Sewing Needle; Transcutaneous Extrusion of Foreign Body; Self Extrusion of Foreign Body

\section{Introduction}

Sharp foreign bodies such as fish bones, dentures, wires, and needles have a tendency to stick in the mucosa of pharynx and the gastrointestinal tract. Rarer outcomes for ingested foreign bodies include migration of the foreign bodies into the soft tissues of the neck [1] or even the mediastinum [2]. A migrated foreign body has the potential to cause suppurative as well as vascular complications [3]. Spontaneous extrusion of an ingested foreign body via the skin of the neck has rarely been reported.

Commonly migrated foreign bodies reported are fish bones from the population dependent on sea foods; uncommon are needles, toothpicks, wires, hairpin and dentures [3-5]. These have been found at various sites including the thyroid gland [6], common carotid artery [7], and mediastinum [2]. These foreign bodies in the neck had caused deep neck abscess [3,4], haematoma [3], thyroid swelling [6], injury to vessels $[3,7,8]$ and even pseudoaneurysm of aorta [7].

A migrated foreign body usually diagnosed with negative endoscopy with positive radiology cases. Rarely these cases first present with complication due to migration. In such situations, a CT scan is necessary to localize the foreign body and exclude suppurative and vascular complications $[1,4]$.

\section{Case Report}

A 46-year-old male patient presented to us with a sharp protruded swelling left side of the neck for $6 \mathrm{hrs}$ (Figure 1). The protrusion was at the level of cricoid cartilage 1.5 $\mathrm{cm}$ left to midline. Patient reported slight pain in throat for 2 days. Indirect laryngoscopy and telelaryngoscopic examination was normal and no foreign body could be visualized. No bleeding spot identified.

PA and lateral skiagram showed presence of radioopaque metallic foreign body suggesting a sewing needle (Figures 2(a) and (b)). The foreign body appeared to be migrating from left pyriform fossa in the soft tissue of the neck. Patient recollected the possibility of presence of sewing needle in some sweets placed on a paper. He folded the paper and had it directly in his mouth. Patient has not noticed the presence of needle but experienced some pain in throat after that.

A contrast enhanced CT scan neck was done to see the relationship of foreign body to great vessels. CT scan showed the foreign body tracked medial and distant to great vessels (Figure 3). As the sharp end of foreign body was protruding through skin; transcutaneous removal of foreign body was planned. Surgery was done under general anesthesia. Small incision made at the protrusion site, sharp end of foreign body needle identified 


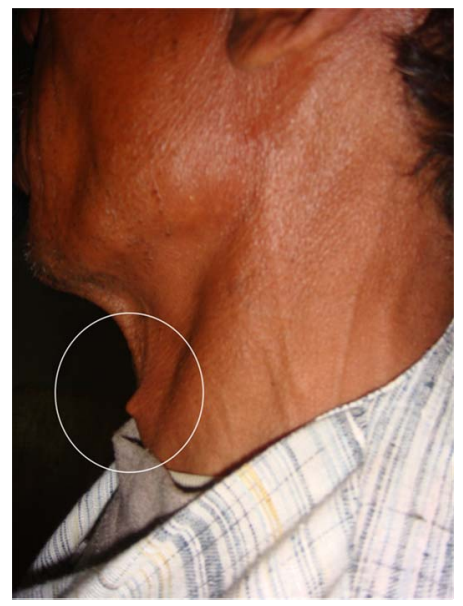

Figure 1. Sharp projection by foreign body.

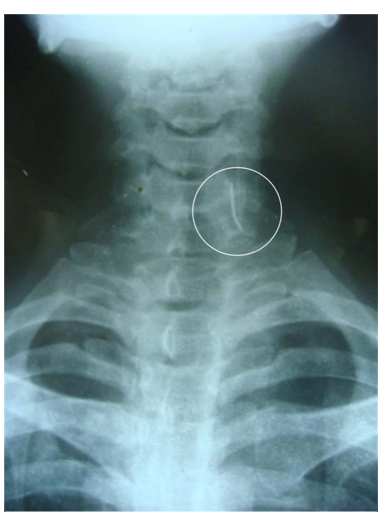

(a)

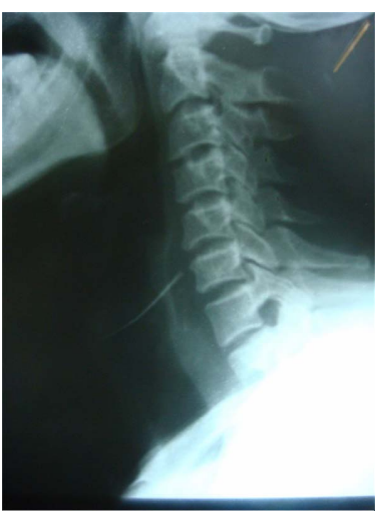

(b)
Figure 2. (a), (b) PA \& lateral skiagram showing position of foreign body.

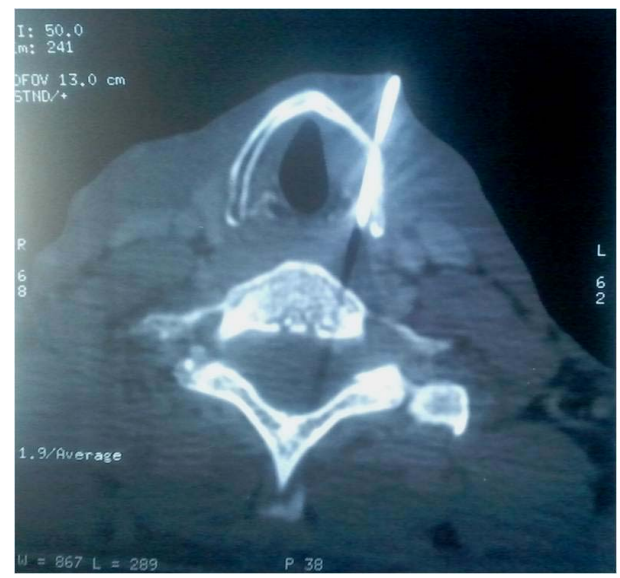

Figure 3. CT scan axial cut showing the path taken by foreign body sewing needle from apex of left pyriform fossa to skin of neck.

in subcutaneous tissue and foreign body was delivered out gently (Figure 4). Foreign body was a slightly bent sewing needle of $4 \mathrm{~cm}$ length (Figure 5). Single stitch with 3-0 Ethilon placed to close the wound. Postopera-

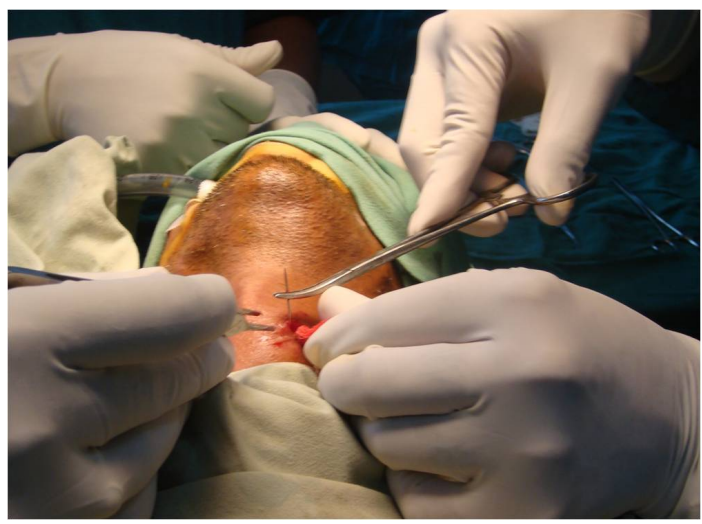

Figure 4. Transcutaneous removal of foreign body.

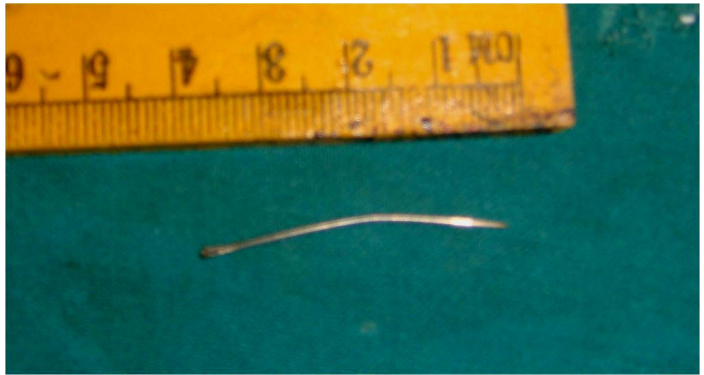

Figure 5. Foreign body sewing needle.

tive recovery was uneventful.

\section{Discussion}

Foreign body ingestion is a common presentation. Commonly children present with foreign body coin ingestion while in adults usual foreign bodies are fish bone, meat bolus and dentures. Migration of foreign body usually takes $24-72 \mathrm{hrs}$ and usually are forgotten cases or not taken seriously by patients or not properly investigated. Usually migration is noticed after a negative endoscopy with positive skiagram [4].

Most ingested foreign bodies pass through the gastrointestinal tract uneventfully within one week [5]. One of the uncommon complications of ingested foreign bodies is migration, which has the potential to cause morbidity and mortality $[4,5]$.

Chee et al. in a retrospective study found 24 patients with migrated fish bones in Singapore General Hospital [4]. Chung et al. presented 4 cases of migrated fish bones to the neck. In the first case, this caused a recurrent deep neck infection for 2 years; in the second case, there was penetration of the facial artery, in third, there was a hematoma of the floor of the mouth and in fourth case, there was a retropharyngeal abscess [3]. Goh et al. reported 4 cases of transesophageal migration of fish bone into thyroid gland [6]. Migration of ingested foreign body to mediastinum [2], liver [5], mesentry [9], and even external iliac vein [10] has been reported. The me- 
chanism of migration is thought to be due to movement of neck muscle and viscera during voluntary or involuntary movements [11]. Large foreign bodies such as fish bones, pins or wires are assisted in their migration by contraction of neck muscle especially the cricopharyngeus muscle during swallowing. The shapes of the foreign bodies also contribute to the rate of migration [11].

Tan AK et al. have suggested a preoperative CT scan of the neck before attempting removal of foreign body in such cases as it tells about the path taken by the foreign body in migrating to the skin and excludes vascular complications such as a pseudoaneurysm of the great vessels of the neck, or the foreign body embedded in great vessels, removal of which could trigger a fatal haemorrhage [1]. CT scan also rules out suppurative complications such as a deep neck abscess [3].

\section{Conclusion}

Self-extrusion of a migrated ingested foreign body via the skin of the neck can be a result of neglected or undiagnosed foreign body and is indeed a rare occurrence. CT scan of the neck helps in early diagnosis of such misplaced or suspected foreign bodies and to planning for surgery. CT also helps in diagnosing any complication caused by the foreign body migration or impending complication which might occur during removal. Lastly a foreign body peeping out of the neck should not be pulled casually as fatal complication may occur.

\section{REFERENCES}

[1] A. K. Tan, P. P. Hsu and P. K. Lu, "Self-Extrusion of a Foreign Body from the Upper Digestive Tract to the Skin," Journal of Laryngology and Otology, Vol. 118, No. 3, 2004, pp. 242-243. doi:10.1258/002221504322928080

[2] O. Rückbeil, J. Burghardt and K. Gellert, "Thoracoscopic Removal of a Transesophageal Ingested Mediastinal Foreign Body," Interactive Cardiovascular and Thoracic Surgery, Vol. 9, No. 3, 2009, pp. 556-557. doi:10.1510/icvts.2009.209676

[3] S. M. Chung, H. S. Kim and E. H. Park, "Migrating Pharyngeal Foreign Bodies: A Series of Four Cases of Saw-
Toothed Fish Bones," European Archieves of Otorhinolaryngology, Vol. 265, No. 9, 2008, pp. 1125-1129. doi:10.1007/s00405-007-0572-x

[4] L. W. Chee and D. S. Sethi, "Diagnostic and Therapeutic Approach to Migrating Foreign Bodies," Annals of Otology, Rhinology, and Laryngology, Vol. 108, No. 2, 1999, pp. 177-180.

[5] M. N. Azili, A. Karaman, I. Karaman, D. Erdoğan, Y. H. Cavuşoğlu, M. K. Aslan, et al., "A Sewing Needle Migrating into the Liver in a Child: Case Report and Review of the Literature," Pediatric Surgery International, Vol. 23, No. 11, 2007, pp. 1135-1137. doi:10.1007/s00383-007-1914-X

[6] Y. H. Goh and N. G. Tan, "Penetrating Oesophageal Foreign Bodies in the Thyroid Gland," Journal of Laryngology and Otology, Vol. 113, No. 8, 1999, pp. 769-771. doi:10.1017/S0022215100145165

[7] C. Ferro, U. G. Rossi, G. Bovio, M. Dahmane, S. Seitun, R. Santucci, et al., "Images in Cardiovascular Medicine. Aortic Pseudoaneurysm Caused by Migration of a Swallowed Sewing Needle: Interventional Radiology and Endoscopic Management," Circulation, Vol. 118, No. 2, 2008, pp. e11-e15. doi:10.1161/CIRCULATIONAHA.107.753269

[8] I. P. Tang, S. Singh, N. Shoba, O. Rahmat, S. Shivalingam, K. G. Gopala, et al., "Migrating Foreign Body into the Common Carotid Artery and Internal Jugular VeinA Rare Case," Auris Nasus Larynx, Vol. 36, No. 3, 2009, pp. 380-82. doi:10.1016/j.anl.2008.08.003

[9] E. Ergul, M. Ozer, M. R. Aydin and G. Kiyak, "Migration of an Ingested Needle to the Mesentery, Causing Intestinal Necrosis," Acta Chirurgica Belgica, Vol. 107, No. 6, 2007, pp. 726-727.

[10] Y. D. Chen, H. S. Tseng, R. C. Lee, Y. Y. Chiou, J. H. Chiang and C. Y. Chang, "Migration of an Ingested Foreign Body into the Right External Iliac Vein," Journal of Vascular and Interventional Radiology, Vol. 20, No. 3, 2009, pp. 420-22. doi:10.1016/j.jvir.2008.11.028

[11] S. P. Yadav, R. Chanda, P. Malik and S. Chanda, "Ingested Nail Penetrating the Neck in an Infant," International Journal of Pediatric Otorhinolaryngology, Vol. 65, No. 2, 2002, pp. 159-162. doi:10.1016/S0165-5876(02)00149-0 